\title{
Author Correction: Formation of helical membrane tubes around microtubules by single-headed kinesin KIF1A
}

\author{
David Oriola', Sophie Roth ${ }^{2,3}$, Marileen Dogterom ${ }^{2,3} \&$ Jaume Casademunt ${ }^{1}$
}

Correction to: Nature Communications https://doi.org/10.1038/ncomms9025, published online 13 August 2018.

This Article contains an error in the first sentence of the 'KIF1A purification and labelling' section of the Methods, which incorrectly reads 'A construct containing the first 382 residues of KIF1A with a His-tag and a Cys residue in the N-terminal, was kindly provided by N. Hirokawa (University of Tokyo, Japan; see ref. ${ }^{13}$ ).' This should say 'C-terminus' instead of 'N-terminus'. The error has not been fixed in the PDF or HTML versions of the Article.

Published online: 02 July 2019

cc) Open Access This article is licensed under a Creative Commons Attribution 4.0 International License, which permits use, sharing, adaptation, distribution and reproduction in any medium or format, as long as you give appropriate credit to the original author(s) and the source, provide a link to the Creative Commons license, and indicate if changes were made. The images or other third party material in this article are included in the article's Creative Commons license, unless indicated otherwise in a credit line to the material. If material is not included in the article's Creative Commons license and your intended use is not permitted by statutory regulation or exceeds the permitted use, you will need to obtain permission directly from the copyright holder. To view a copy of this license, visit http://creativecommons.org/licenses/by/4.0/.

(c) The Author(s) 2019

\footnotetext{
${ }^{1}$ Departament d'Estructura i Constituents de la Matèria, Facultat de Física, Universitat de Barcelona, Avinguda Diagonal 647, E-08028 Barcelona, Spain. ${ }^{2}$ FOM Institute AMOLF, Science Park 104, 1098 XG Amsterdam, The Netherlands. ${ }^{3}$ Present address: Department of Bionanoscience, Kavli Institute of Nanoscience, TU Delft, Lorentzweg 1, 2628 CJ Delft, The Netherlands. Correspondence and requests for materials should be addressed to D.O. (email: oriola@ecm.ub.edu)
} 